I. Sukhotnik $\cdot$ E. Yakirevich $\cdot$ A.G. Coran $\cdot$ L. Siplovich

M. Krausz · E. Sabo · A. Kramer · E. Shiloni

\title{
Lipopolysaccharide endotoxemia reduces cell proliferation and decreases enterocyte apopotosis during intestinal adaptation in a rat model of short-bowel syndrome
}

Accepted: 28 November 2001 / Published online: 26 September 2002

(C) Springer-Verlag 2002

\begin{abstract}
Sepsis is frequently associated with or complicates short-bowel syndrome (SBS). To investigate the effects of lipopolysaccharide (LPS) endotoxemia on enterocyte proliferation and death via apoptosis in a rat model of SBS, adult male Sprague-Dawley rats were divided into three experimental groups: sham rats underwent bowel transection and reanastomosis; SBS rats underwent $75 \%$ small-bowel resection; and SBS-LPS rats underwent $75 \%$ bowel resection and were given intraperitoneal injections of LPS $10 \mathrm{mg} / \mathrm{kg}$. Parameters of intestinal adaptation (bowel and mucosal weights, mucosal DNA and protein, villus height, and crypt depth), enterocyte proliferation, and death via apoptosis were determined on day 15 after the operation. Statistical analysis was determined by Student's and ANOVA tests with a $P$ less than 0.05 considered significant. SBSLPS animals demonstrated a significant decrease (vs SBS rats) in duodenal $(20 \%)$, jejunal $(30 \%)$, and ileal $(15 \%)$ overall weight, duodenal $(20 \%)$, jejunal $(27 \%)$, and ileal $(18 \%)$ mucosal weight, jejunal $(20 \%)$ and ileal $(30 \%)$ mucosal DNA, jejunal $(29 \%)$ and ileal $(31 \%)$ villus height, and jejunal (14\%) and ileal (29\%) crypt depth. LPS endotoxemia led to reduced cell proliferation and
\end{abstract}

I. Sukhotnik $(\bowtie) \cdot$ E. Yakirevich $\cdot$ L. Siplovich $\cdot$ M. Krausz

E. Sabo · A. Kramer · E. Shiloni

Rappaport Faculty of Medicine,

Technion, Carmel Medical Center,

HaEmek, Medical Center and Rambam Medical Center,

Haifa, Israel

E-mail: igor-dr@internet-zahav.net

Tel.: + 972-4-8250294

Fax: +972-4-8346083

A.G. Coran

Section of Pediatric Surgery,

C.S. Mott Children's Hospital and

University of Michigan Medical School,

Ann Arbor, MI, USA

I. Sukhotnik

Dept Surgery B, Carmel Medical Center,

7 Michal str, Haifa,

Israel, 34362 enterocyte apoptosis compared to untreated SBS animals. Thus, in a rat model of SBS, LPS endotoxemia inhibits intestinal adaptation. A possible mechanism may be decreased cell proliferation. Decreased enterocyte loss via apoptosis may reflect a reduced number of enterocytes. Other mechanisms (necrosis) may be mainly responsible for cell death following LPS injection.

Keywords Short-bowel syndrome $\cdot$ Intestinal adaptation $\cdot$ Lipopolysaccharide $\cdot$ Endotoxemia

\section{Introduction}

Sepsis is a major cause of mortality and morbidity in patients with short-bowel syndrome (SBS). It is closely associated with poor central -venous catheter care or bacterial overgrowth with subsequent bacterial translocation $[9,12]$. Other causes of sepsis in patients with SBS include septic complications of bowel resection and wound and nosocomial infections.

The effect of sepsis on intestinal adaptation has not been studied in SBS as yet. However, an understanding of the pathophysiologic mechanisms by which sepsis influences bowel growth and subsequent nutrient absorption following bowel resection may have important clinical implications. The regulation of cell numbers in the gastrointestinal (GI) tract is determined by the balance between cell production and loss. Under normal circumstances, newly-formed immature enterocytes divide in the crypts of Lieberkühn and migrate up to the villus tip, differentiate, mature, and become functional, playing an important role in the absorption of nutrients.

The increase in villus height and crypt depth following massive bowel resection has been thought to result from cellular hyperplasia, leading to a marked increase in individual cell-surface area and overall absorption capability. Few data are available on the role of apoptosis, or programmed cell death, in preserving enterocyte mass following bowel resection. Recent evidence suggests that apoptosis probably accounts for the bulk of 
cell loss in the gut [5]. Apoptosis is a physiological suicide mechanism maintaining cell homeostasis and turnover. Inappropriate regulation of apoptosis may play an important role in many pathological conditions like ischemia, stroke, cancer, the acquired immuno deficiency syndrome, autoimmune disorders, etc. [8]. Recently, apoptosis has been reported to be an important mechanism of cell death in animal models of sepsis and endotoxemia $[2,18]$.

Enterocyte dysfunction and damage are thought to contribute to GI dysfunction in sepsis. Increased enterocyte apoptosis has been reported in the mouse following i.v. injuction of Lipopolysaccharide (LPS) [2] and in a rat model of polymicrobial peritonitis [6]. We have recently shown that LPS endotoxemia inhibits intestinal adaptation following massive bowel resection in a rat model [14]. The purpose of the present study was to evaluate the mechanism by which endotoxemia influences bowel growth after intestinal resection and to determine its effect on cell proliferation and enterocyte loss via apoptosis.

\section{Materials and methods}

Male Sprague-Dawley rats weighing 250-280 g were divided into three experimental groups: (1) sham control rats (group $\mathrm{A}, \mathrm{n}=$ 14); (2) SBS rats (group B, $\mathrm{n}=14$ ); and (3) rats with SBS treated with LPS (SBS-LPS, group $\mathrm{C}, \mathrm{n}=13$ ). After 3 days of acclimatization under controlled conditions (12-h day/night rhythm, temperature $22{ }^{\circ} \mathrm{C}, 55 \%$ relative humidity), animals were anesthetized with IP phenobarbital $(45 \mathrm{mg} / \mathrm{kg})$.

Using sterile technique, a midline laparotomy was performed. Sham animals underwent transection of the ileum $15 \mathrm{~cm}$ proximal to the ileocecal junction and immediate reanastomosis; $75 \%$ bowel resection was performed, preserving $5 \mathrm{~cm}$ proximal jejunum and $15 \mathrm{~cm}$ distal ileum. The small intestine was reanastomosed end-toend using interrupted sutures of 6-0 silk. In all animals the abdomen was closed in two layers with a running suture of 3-0 Dexon. The animals were allowed water ad libitum on the 1st and normal chow on the beginning of the 2 nd postoperative day (POD).

The animals in group C were treated with LPS IP $10 \mathrm{mg} / \mathrm{kg}$ every $24 \mathrm{~h}$ from POD 9 through 14 . On the morning of the 15 th day, animals were anesthetized with IP sodium pentobarbital $(45 \mathrm{mg} / \mathrm{kg}$ ) and killed by open pneumothorax. The remaining small intestine was harvested and divided into three segments: duodenum, jejunum to anastomosis, and terminal ileum. Each segment was washed with ice-cold saline, weighed, and the weight per $\mathrm{cm}$ bowel length was calculated. The mucosa was scraped off, weighed, and snap-frozen in liquid nitrogen. Mucosal samples (100 mg) were homogenized using a Kontes Tenbroeck tissue grinder. DNA and protein were extracted using TRIZOL reagent as described by Chomczynski [4]. The DNA concentrations were recorded spectrophotometrically and calculated per $\mathrm{cm}$ bowel length. The final protein concentration was measured spectrophotometrically using a commercially available kit (Bio-Rad protein assay) and calculated per $\mathrm{cm}$ bowel length.

Histologic sections were prepared from the jejunal and ileal remnants. Pieces of intestine were fixed for $24 \mathrm{~h}$ in $5 \%$ formalin, washed with absolute alcohol, and embedded in paraffin, with transverse $5-\mu \mathrm{m}$ sections prepared in a standardized fashion. The slides were stained with hematoxylin and eosin. Histologic images were loaded on a $760 \times 570$-pixel resolution buffer using a computerized image analysis system composed of a trichip RGB video-camera (Sony, Japan) installed on a light microscope (Zeiss, Germany) and attached to an IBM-compatible personal computer (Pentium III, MMX, $450 \mathrm{MHz}, 125 \mathrm{MB}$ RAM) equipped with a frame grabber. Images were captured, digitized, and displayed on a high-resolution, 17-inch color monitor. The villus height and crypt depth were measured using the Image Pro Plus 4 image analysis software (Media Cybernetics, Baltimore, MD).

Rats were injected with standard 5-bromodeoxyuridine (5BrdU)-labeling reagent (Zymed CA) $1 \mathrm{ml} / 100 \mathrm{~g}$ body weight $2 \mathrm{~h}$ before death. Proliferating epithelial cells were identified by immunohistochemistry with anti-BrdU monoclonal antibody using a BrdU staining kit (Zymed). An index of proliferation (PI) was determined as the ratio of crypt cells staining positively for $\mathrm{BrdU}$ per 10 crypts.

Apoptosis of enterocytes was assessed by terminal deoxyuridine nick-end labeling (TUNEL) immunohistochemical assay using the I.S. cell death detection kit for immunohistochemical detection and quantification of apoptosis at single-cell level, based on labeling of DNA strand breaks: analysis by light microscopy (Boehringer Mannheim, Mannheim, Germany). AES substrate (Zymed) was applied for color development. For each group, the number of stained cells was counted in at least 10 villi in areas without necrosis. The apoptotic index (AI) was defined as the number of apoptotic TUNEL-positive cells per 1,000 villus cells.

A qualified pathologist blinded to the source of intestinal tissue performed all measurements.

The data are expressed as mean \pm standard error (SEM). A paired Student's $t$-test and non-parametric Kruskal-Wallis ANOVA test were used for statistical analysis, with $P$ less than 0.05 considered statistically significant.

\section{Results}

Final body weight (BW)

SBS rats demonstrated a significant decrease in final BW compared to sham animals $(99 \pm 2$ vs $107 \pm 2, P<$ 0.05). Following injection of LPS, SBS rats showed an additional $13 \%$ decrease in BW compared to untreated SBS animals $(87 \pm 2$ vs $99 \pm 2, p<0.05)$.

\section{Structural adaptation changes}

SBS rats (group B) showed a marked increase in overall bowel and mucosal weights in the duodenum $(36 \%$ and $50 \%$, respectively, $P<0.05)$, jejunum $(173 \%$ and $188 \%, P<0.05)$ and ileum $(67 \%$ and $52 \%, P<0.05)$ compared to sham animals. In addition, SBS rats demonstrated a three-fold increase in mucosal DNA and protein in the jejunum and a significant increase in mucosal DNA $(33 \%, P<0.05)$ and protein $(32 \%, P<$ 0.05 ) in the ileum compared to sham animals (Table 1). Microscopic analysis of the remaining intestine 2 weeks after bowel resection revealed characteristic changes of intestinal adaptation (Fig. 1). SBS rats demonstrated a significant $54 \%$ increase in jejunal villus height and a significant $23 \%$ increase in both jejunal and ileal crypt depth compared to sham animals. Although the ileum of SBS rats manifested a tendency toward longer, cytoarchitecturally preserved villi compared to sham rats, this trend did not achieve statistical significance.

Following LPS administration SBS rats showed significantly decreased overall bowel weight in the duodenum $(20 \%, P<0.05)$, jejunum $(30 \%, P<0.05)$, and ileum $(15 \%, P<0.05)$ and decreased mucosal weight in 
Table 1 Parameters of structural intestinal adaptation ( $S B S$ short-bowel syndrome, $L P S$ lipopolysaccharide)

${ }^{\mathrm{a}} P<0.05$ SBS vs sham rats

${ }^{\mathrm{b}} P<0.05$ SBS-LPS vs SBS rats

\begin{tabular}{|c|c|c|c|c|}
\hline Parameter of adaptation & $\begin{array}{l}\text { Intestinal } \\
\text { segments }\end{array}$ & $\begin{array}{l}\text { Sham } \\
\text { rats }\end{array}$ & $\begin{array}{l}\text { Untreated } \\
\text { SBS rats }\end{array}$ & $\begin{array}{l}\text { SBS-LPS } \\
\text { rats }\end{array}$ \\
\hline $\begin{array}{l}\text { Bowel Weight } \\
(\mathrm{mg} / \mathrm{cm})\end{array}$ & $\begin{array}{l}\text { Duodenum } \\
\text { Jejunum } \\
\text { Ileum }\end{array}$ & $\begin{array}{l}88 \pm 4 \\
75 \pm 5 \\
73 \pm 4\end{array}$ & $\begin{array}{l}120 \pm 4^{\mathrm{a}} \\
205 \pm 18^{\mathrm{a}} \\
122 \pm 6^{\mathrm{a}}\end{array}$ & $\begin{array}{r}96 \pm 1^{\mathrm{a}, \mathrm{b}} \\
144 \pm 7^{\mathrm{a}, \mathrm{b}} \\
104 \pm 7^{\mathrm{a}, \mathrm{b}}\end{array}$ \\
\hline $\begin{array}{l}\text { Mucosal Weight } \\
(\mathrm{mg} / \mathrm{cm})\end{array}$ & $\begin{array}{l}\text { Duodenum } \\
\text { Jejunum } \\
\text { Ileum }\end{array}$ & $\begin{array}{l}30 \pm 2 \\
26 \pm 2 \\
25 \pm 2\end{array}$ & $\begin{array}{l}45 \pm 3^{\mathrm{a}} \\
75 \pm 5^{\mathrm{a}} \\
38 \pm 2^{\mathrm{a}}\end{array}$ & $\begin{array}{l}36 \pm 2^{\mathrm{a}, \mathrm{b}} \\
55 \pm 4^{\mathrm{a}, \mathrm{b}} \\
31 \pm 1^{\mathrm{a} \cdot \mathrm{b}}\end{array}$ \\
\hline $\begin{array}{l}\text { Mucosal DNA } \\
(\mu \mathrm{g} / \mathrm{cm}) \\
\text { Mucosal Protein } \\
(\mu \mathrm{g} / \mathrm{cm})\end{array}$ & $\begin{array}{l}\text { Jejunum } \\
\text { Ileum } \\
\text { Jejunum } \\
\text { Ileum }\end{array}$ & $\begin{array}{l}39 \pm 5 \\
46 \pm 3 \\
66 \pm 8 \\
72 \pm 7\end{array}$ & $\begin{aligned} 116 & \pm 9^{\mathrm{a}} \\
61 & \pm 3^{\mathrm{a}} \\
171 & \pm 21^{\mathrm{a}} \\
95 & \pm 7^{\mathrm{a}}\end{aligned}$ & $\begin{aligned} 93 & \pm 9^{\mathrm{a}, \mathrm{b}} \\
43 & \pm 4^{\mathrm{a}, \mathrm{b}} \\
130 & \pm 22^{\mathrm{a}} \\
68 & \pm 11^{\mathrm{a}, \mathrm{b}}\end{aligned}$ \\
\hline
\end{tabular}

the duodenum $(20 \%, P<0.05)$, jejunum $(27 \%, P<$ $0.05)$ and ileum $(18 \%, P<0.05)$ compared to nontreated SBS animals. SBS-LPS rats also demonstrated a decrease in jejunal $(20 \%, P<0.05)$ and ileal $(30 \%, P<$ $0.05)$ mucosal DNA and a decrease in ileal protein $(28 \%, P<0.05)$ compared to SBS animals. LPS endotoxemia in the resected animals was associated with a significant loss of villus height in the jejunum $(29 \%, P<$ $0.05)$ and ileum $(31 \%, P<0.05)$ and a decrease in crypt depth in the jejunum $(14 \%, P<0.05)$ and ileum $(29 \%$, $P<0.05)$ compared to untreated SBS rats.

\section{Cellular proliferation and apoptosis}

A significant increase in enterocyte proliferation was observed in rats following massive bowel resection compared to sham animals in both jejunum (PI $549 \pm$ 52 vs $302 \pm 34$ BrdU-positive cells $/ 10$ crypts, $P<0.05$ ) and ileum $(530 \pm 40$ vs $368 \pm 65, P<0.05)$. LPS endotoxemia resulted in a significant decrease in cell proliferation compared to resected, untreated rats. SBSLPS animals demonstrated a lower enterocyte proliferation rate in ileum compared to untreated SBS rats (PI $380 \pm 45$ vs $530 \pm 40 P<0.05$ ) (Fig. 2).

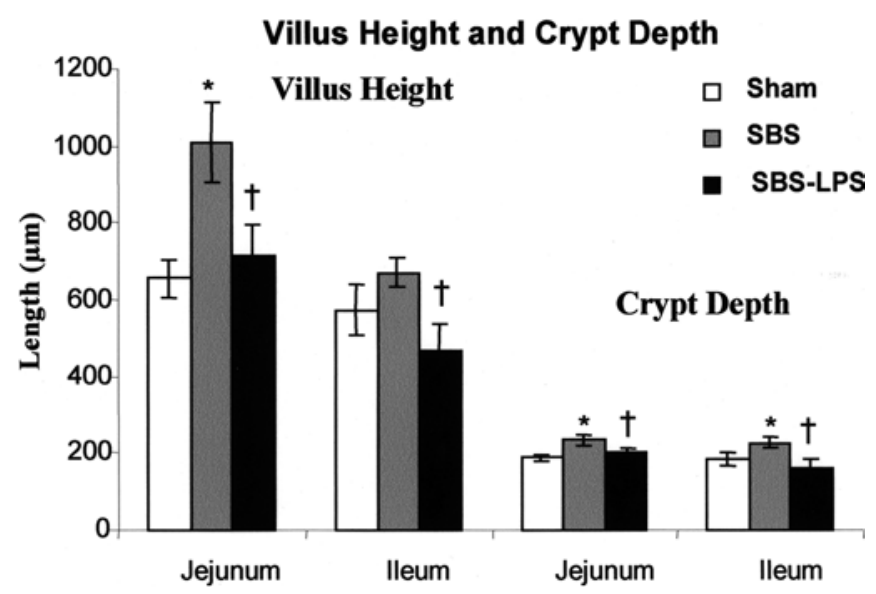

Fig. 1 Effect of bowel resection and lipopolysaccharide (LPS) endotoxemia on microscopic appearance of rat small intestine 14 days following bowel resection ( $S B S$ short-bowel syndrome, ${ }^{*} P<$ 0.05 SBS vs sham rats, $\uparrow P<0.05$ SBS-LPS vs SBS rats)
We next determined whether bowel resection and endotoxemia altered enterocyte apoptosis. The jejunum showed no significant increase in apoptosis following bowel resection compared to sham animals, while the ileum showed a significant increase in AI $(22 \pm 3$ vs $12 \pm 4$ apoptotic cells 1,000 cells, $P<0.05$ ) (Fig. 3). The AI decreased following LPS administration in the ileum $(5 \pm 1$ vs $22 \pm 3$ apoptotic cells $/ 1,000$ cells, $P<0.05)$ compared to untreated SBS animals. Although not statistically different, the trend was the same in jejunal apical villi in SBS-LPS compared to SBS rats.

\section{Discussion}

SBS is defined as the spectrum of malabsorption and malnutrition resulting in an insufficient nutrient supply due to reduction of intestinal absorptive surface area $[13,15]$. Despite the availability of total parenteral

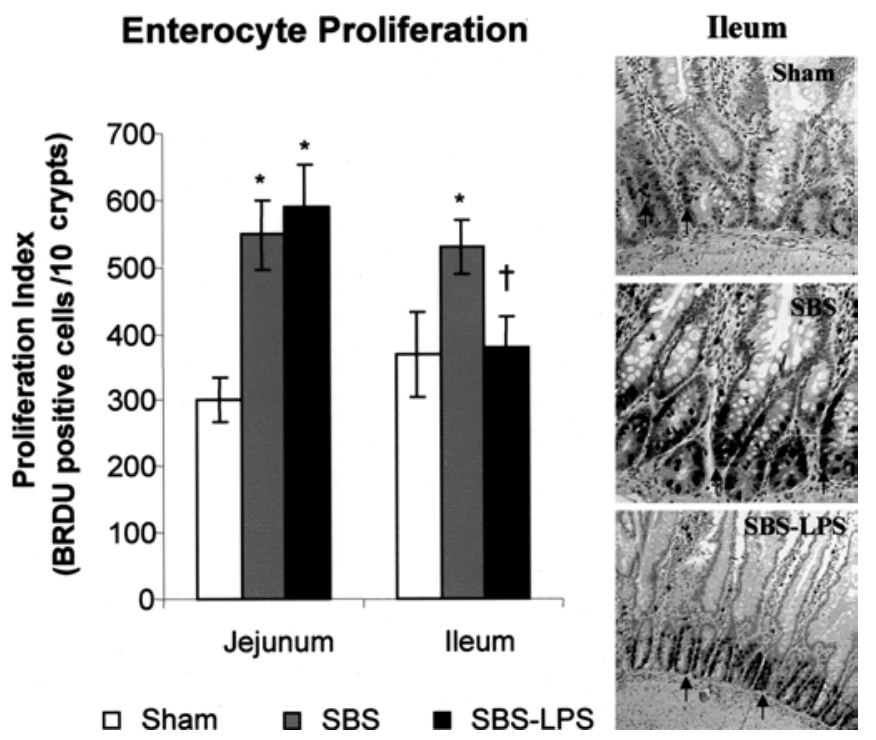

Fig. 2 Effect of bowel resection and low-fat diet on crypt-cell proliferation in jejunum and ileum. Number of labeled cells in 10 well-oriented, longitudinal crypts per section from each rat was determined using light microscopy (mean \pm SEM) (SBS shortbowel syndrome rats, $L P S$ lipopolysaccharide, ${ }^{*} P<0.05$ SBS vs sham rats, $\dagger P<0.05$ SBS-LPS vs SBS rats) 


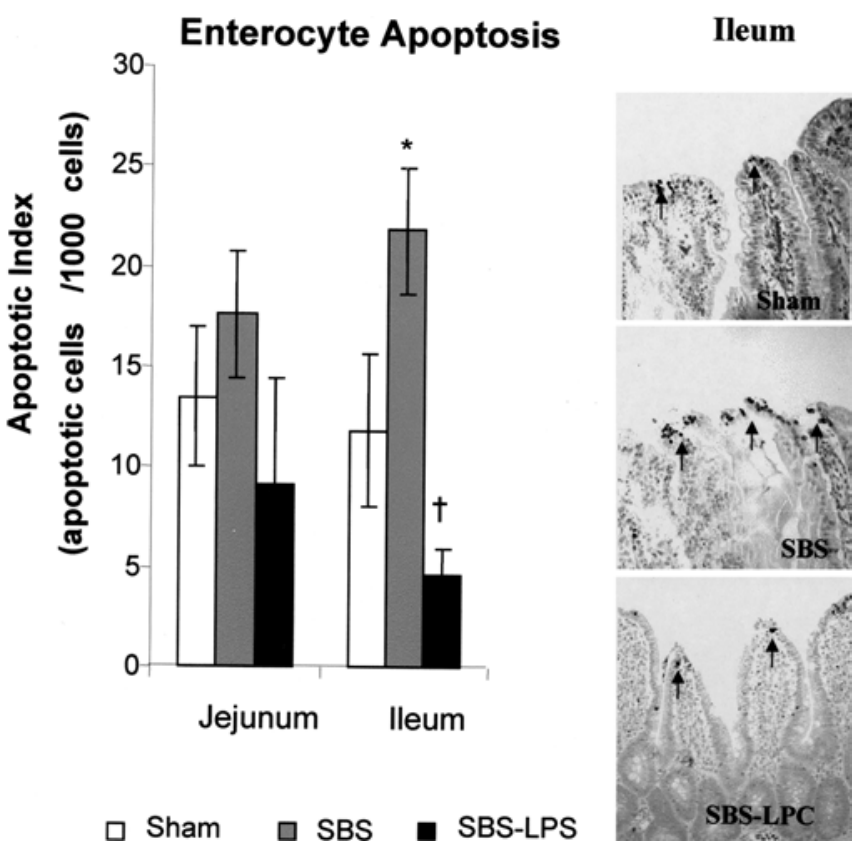

Fig. 3 Effect of bowel resection and dietary treatment on enterocyte apoptosis (TUNEL assay) (SBS short-bowel syndrome, LPS lipopolysaccharide, $* P<0.05$ SBS vs sham rats, $\dagger P<0.05$ SBSLPS vs SBS rats

nutrition (TPN), advances in resuscitation, the availability of potent antibiotics, and modern techniques of organ support, the current morbidity of SBS remains strikingly high [3]. The key to survival after massive small-bowel resection is the ability of the residual bowel to adapt.

"Adaptation" is the term applied to the progressive recovery from intestinal failure following a loss of intestinal length and is characterized by increases in wet weight, protein, and mucosal DNA content, villus height, crypt depth, and absorptive surface area (structural adaptation) [10]. In addition to morphologic alterations, functional changes in the individual enterocytes also occur and include increased nutrient and micronutrient transport by isolated enterocytes [11]. Several factors may stimulate bowel growth or increase the carrier capacity of individual enterocytes. Over the last 4 decades, much research has focused on the documentation and identification of factors promoting gut regeneration. Little is known about those factors that may inhibit intestinal adaptation.

Sepsis is commonly associated with or complicates SBS [11], and is often related to central-venous catheters (CVC) or bacterial overgrowth within the bowel. Because the majority of patients with SBS require TPN, most episodes of sepsis have been attributed to the CVC. However, a growing body of evidence suggests the role of gut barrier failure and bacterial translocation as an additional potential contributor to sepsis following massive bowel resection [10]. It has been reported that the incidence of septic episodes is related to the remaining bowel length, which supports the notion that infection results mainly from an increase in intestinal permeability rather than from poor CVC care. Decreased bowel motility and a reduction in gut-associated lymphoid tissue might decrease the local immune response and increase the bacterial content of the small intestine. On the other hand, sepsis can itself lead to increased permeability of the intestinal mucosal barrier, i.e., the passage of bacteria or their products such as endotoxin from the intestinal lumen into the portal bloodstream with activation of Kupffer cells, resulting in the secretion of pro-inflammatory and hypotensive substances [17].

Surprisingly, in reviewing the literature we were not able to find a single report investigating the effects of septicemia/endotoxemia on intestinal adaptation. Sepsis may affect bowel growth and exacerbate malabsorption by several mechanisms. In addition to inadequate GI perfusion [1], resulting in alterations of mucosal oxygenation and acidosis, the mechanisms of GI dysfunction in sepsis also include either direct or indirect intestinal damage by one or more substances released into the bloodstream and disseminated intravascular coagulation with formation of microvascular thrombi in the GI tract [7]. Inflammation of the mucosa from bacterial overgrowth, increased deconjugation of bile salts by bacteria with concomitant bile-salt deficiency, and motility disorders of the remaining gut should be considered additional factors predisposing to malabsorption [16].

We have recently shown an inhibitory effect of LPS endotoxemia on intestinal proliferation [14], and designed the present study to evaluate the mechanisms by which LPS endotoxemia affects intestinal adaptation following bowel resection in a rat model. Our data demonstrate that endotoxemia has inhibitory effects on mucosal regrowth after bowel resection. The observed decreased bowel and mucosal weight, decreased mucosal DNA and protein, and decreased villus height and crypt depth in this model support this conclusion. This impaired adaptive response was accompanied by a decrease in enterocyte production and enterocyte loss via apoptosis. Decreased cell proliferation is probably the main mechanism responsible for the decreased enterocyte mass following endotoxemia. It is not clear if the reduced apoptosis reflects decreased enterocyte mass, or represents an adaptive mechanism that maintains mucosal structure following LPS administration. Further studies are required to determine the role of factors other than apoptosis in cell injury and death (necrosis and oncosis) and the associated reduced cellular mass in rats with SBS treated with LPS.

\section{References}

1. Bersten A, Sibbald WJ (1989) Circulatory disturbances in multiple systems organ failure. Crit Care Clin 5: 233-254

2. Bohlinger I, Leist M, Gantner F, Angermuller S, Tiegs G, Wendel A (1996) DNA fragmentation in mouse organs during endotoxic shock. Am J Pathol 149: 1381-1393 
3. Coran AG, Spivak D, Teitelbaum DH (1999) An analysis of the morbidity and mortality of short bowel syndrome in the pediatric age group. Eur J Pediatr Surg 9: 228-230

4. Chomczynski P (1993) A reagent for the single-step simultaneous isolation of RNA, DNA and proteins from cell and tissue samples. Biotechniques 15: 532-536

5. Hall PA, Coates PJ, Ansari B, Hopwood D (1994) Regulation of cell number in the mammalian gastrointestinal tract: the importance of apoptosis. J Cell Sci 107: 3569-3577

6. Hiramatsu M, Hotchkiss RS, Karl IE, Buchman TG (1997) Cecal ligation and puncture (CLP) induces apoptosis in thymus, spleen, lung, and gut by an endotoxin and TNF-independent pathway. Shock 7: 247-253

7. Levi M, ten Cate H, van der Poll T, van Deventer SJH (1993) Pathogenesis of disseminated intravascular coagulation in sepsis. JAMA 270: 975-979

8. Majno G, Joris I (1995) Apoptosis, oncosis, and necrosis: an overview of cell death. Am J Pathol 146: 3-15

9. Mayr JM, Schober PH, Weißensteiner U, Höllwarth ME (1999) Morbidity and mortality of the short-bowel syndrome. Eur J Pediatr Surg 9: 231-235

10. O' Brien DP, Nelson LA, Huang FS, Warner BW (2001) Intestinal adaptation: structure, function, and regulation. Semin Pediatr Surg 10: 56-64

11. Robinson MK, Ziegler TR, Wilmore DW (1999) Overview of intestinal adaptation and its stimulation. Eur J Pediatr Surg 9: 200-206
12. Schimpl G, Feierl G, Linni K, Uitz C, Osbey H, Hollwarth ME (1999) Bacterial traslocation in short-bowel syndrome in rats. Eur J Pediatr Surg 9: 224-227

13. Sigalet DL (2001) Short bowel syndrome in infants and children: an overview. Semin Pediatr Surg 10: 49-55

14. Sukhotnik I, Krausz MM, Sabo E, Resnick M, Hirsh M, Mannheim M, Shiloni E (2001) Endotoxemia inhibits intestinal adaptation in a rat model of short bowel syndrome. Shock 15 [Suppl]: 56-57

15. Vanderhoof JA (1996) Short bowel syndrome. Neonat Gastroenterol 23: 377-386

16. Vanderhoof JA, Sharon MM (1999) Enteral and parenteral nutrition in patients with short-bowel syndrome. Eur J Pediatr Surg 9: 214-219

17. Yu P, Martin CM (2000) Increased gut permeability and bacterial translocation in Pseudomonas pneumonia-induced sepsis. Crit Care Med 28: 2573-1577

18. Zhang XM, Morikawa A, Takahashi K, Jiang GZ, Kato Y, Sugiyama T, Kawai M, Fukada XM, Yokochi T (1994) Localization of apoptosis (programmed cell death) in mice by administration of lipopolysaccharide. Microbiol Immunol 38: $669-671$ 